\title{
ON THE FORGING OF CRANK SHAFTS.
}

By Mr. W. L. E. MoLEAN, of Glasgow.

The following paper describes the method of forging marine crank-shafts adopted at the Lancefield Forge, Glasgow. It will be better understood if a short account is first given of the ordinary methods in use for the same purpose.

First Method.-The most common method is technically termed by the forgeman "finishing the piece before him." He begins with a staff or stave, as shown in Fig. 1, Plate 59, suspended by a chain from the crane, and made round for the convenience of manipulating under the steam-hammer; this stave is used over and over again for many forgings, as it is merely. the "porter" to carry the piece, and enable it to be worked. The forging is begun by two or three slabs being placed on the stave as at $S$, and then inserted in the furnace. These slabs are flat blocks made up of pieces of scrap iron, which have been piled and heated and then welded together. After being brought to a welding heat in the furnace the slabs are withdrawn, placed under the steam-hammer, and beaten down solid. The piece is then turned upside down, and two or three similar slabs placed on the opposite side, as shown at $S$, Fig. 2. When sufficient iron has been thus added to form the collar of the shaft (assuming it is to have a collar), it is rounded under the hammer, as at $\mathrm{C}$, Fig. 3, and the body of the shaft next to the collar is roughly formed, as at $\mathbf{D}$. More slabs $\mathbf{S}$ are added to bring out the body, and afterwards the crank itself is proceeded with. The piece will begin to assume the appearance as at A, Fig. 4. Then more slabs are welded on the top, as at S, Fig. 4, till the depth of the crank is obtained; after which the forgeman proceeds 
to finish the collar and body of the shaft, as shown in Fig. 5. The collar on being finished is out all round, as shown at C C, Fig. 5, so that it may be more easily detached from the stave when the shaft is completed, leaving only sufficient connection to carry it till then. The forgeman then cuts the gable of the crank as at E G, and rounds up the body $\mathrm{B}$ and neck $\mathrm{N}$.

This it will be observed is a speedy process, and would invariably be adopted if it were not attended with a very serious drawback; it is very hazardous to the solidity of the forging. For it will be easily understood that not above a third of the crank itself can be thus formed, because the iron at the neck $\mathrm{N}$ would not carry a greater mass; if the whole mass of the crank, or even the half of it, was formed before the body and neck of the shaft were finished, a proper heat could not be taken on the body and neck for finishing, without the neck giving way or rupturing. Indeed, as it is, the undue proportion often causes the shaft to be strained at this part, where most strength should be, so that it is rendered weak, and a flaw is developed which by-and-by causes it to be removed from the steamer as dangerous and useless, if indeed it does not break outright; so that the forgeman, if he adopts this method, must be very careful to proportion the amount of iron he has massed in the furnace to the size of the body he is finishing, otherwise the weakening above mentioned will take place. All marine engineers will easily recognise this defect, which frequently occurs, but the cause of which is probably not well understood. Such a flaw will present a similar appearance to that shown at F, Fig. 6, taken from an actual example.

This difficulty of proportioning the part of the crank first forged to the size of the neck, will be still better understood by the appearance of it in the furnace, as shown in Fig. 7. Having reached this stage, with one end of the shaft completed, as also that portion of the crank itself which of necessity was completed before the collar was cut, in order that the neck might be finished, no more iron can be added on the top edge, as it is up to the full depth already; it must therefore be added on the flat, as in Fig. 8, where the piece is shown on its flat side in the furnace, the finished portion being ontside the furnace door. A number of slabs $\mathbf{S}$ are then placed side by 
side to bring out the width of the crank further; these being welded down, the piece is turned upside down, and the process repeated on the other side. Afterwards other slabs are similarly placed on both sides, as shown in Figs. 9 and 10, Plate 60, of which one is the flat and the other is the edge view of the crank at this stage; and this is continued till sufficient iron has been massed to allow of the other gable of the crank being cut down, as at A, Fig. 11, and sufficient also to allow of the other part of the body $B$ being rounded and prepared for further piecing out.

Now it will be observed that the first gable finished has the slabs all welded on the edge of the crank, as shown in Figs. 3,4 , and 5 . and the hammering has all been on the edge; hence the subsequer.t hammering on the flat has a tendency to open up the weldings, if they havo not been thoroughly made. A section taken at A B, Figs. 7 and 8, will show as in Fig. 12, the weldings being across the web of the crank; the dotted circle indicates the section which the crank-pin would present if cut through there. But when the slabs are placed on the flat afterwards, some of the joinings of the ends of the slabs, or "scarf ends," are certain to fall within the crank-pin, as seen in Figs. 8, 9, and 10 ; therefore the section through $\mathrm{CD}$, Figs. 8 and 9, will show somewhat like Fig. 13, where the dotted circle indicates the position of the crank-pin. The flaw thus produced, called "a scarf end in the pin," is readily recognisable by all marine engineers; at $\mathrm{E}$, Fig. 14, is a sketch from actual occurrence.

When the second gable is cut, and the other end is rounded, there is only the other collar to put on (if a double-collared shaft), and the forging is completed.

This metbod is so speedy as compared with any other, that it is often resorted to even at the risk of making a bad forging; ano too many broken shafts testify to the fact. Besides it may be observed that in making a double-crank shaft, while the one crank may be made in this way, the other must; for the first crank A (Fig. 15) being completed, and also the body $B$ between the two cranks, the second crank $\mathrm{C}$ must of necessity be pieed off this body, even at the risk of the neck $\mathrm{N}$ being strained. This may account for the many instances in which one of the cranks of a double- 
crank shaft gives way, rendering the shaft useless; and also for the plan now almost universal of making the two cranks separately and coupling them together; a further object being, no doubt, to have the means of replacing a defective half, if need be, without losing the whole shaft. At Lancefield, when a double-crank shaft is to be made, the after crank A, Fig. 15, is first made by the method afterwards described, so as to ensure that this crank, through which, as being next the propeller, all the power of the engine passes, shall be perfectly sound; and in piecing the other crank off the body, it is worked with slabs on the flat instead of on the edge, as afterwards described.

The writer's own opinion is that the crank is the most important part of the shaft, and therefore, at all costs, should be made first. Others, no doubt, may take the same view, and to aroid the risks just mentioned may adopt the following method.

Second Method.-This method builds the middle first, and is called "turning the shaft end for end." The shaft is begun from a stave, by the addition of slabs, as shown in Figs. 1 and 2. Fig. 16, Plate 60, shows it with iron added in slabs, till a butt is formed as at $B$, to form the nucleus of the crank; slabs $S$ are then piled on, to bring the crank up to the height. These are beaten down and welded, and more are added, as at S, Fig. 17, till the full height of the crank is reached. Should the web (or edgeway of the crank) be thick, two slabs are frequently used to make up the breadth, placed edge to edge, as shown at S, Fig. 18; the width of these slabs being limited by that at which the shinglers can conveniently work and turn them under the steam-hammer. The crank however is completed without any "side slabs," such as shown in Figs. 8, 9, 10; for the beating down of the slabs on the edge broadens out the mass, and gives sufficient material to forge out the crank to the proper height by hammering on the flat. The crank is afterwards cut at the off gable at G, Fig. 19, Plate 61, the body B pieced out and rounded, the collar welded on, and then a small stave $S$ is drawn upon the end, to enable the forgeman to handle the piece when he "turns it end for" end," in order to complete the other end of the shaft. 
This method, though better than the first, is also objectionable; for though there is not equal risk of "scarf ends" in the pin, yet the weldings are all on the edge, as shown at T, Fig. 20, where the section of the crank-pin is shown by the dotted circle; and the cheeks of the crank O O, Fig. 21, are thus liable to give way if a heavy strain comes on the crank when at work. The defects arising from this cause are shown in Figs. 22, 23, and will be readily recognised by all engineers.

Third Method,-Considerations such as these have led to the adoption of the third or Lancefield method. Fig. 24, Plate 61, shows the piece begun from the stave in the usual way, with the slabs however all welded on the flat, till a basis is formed for the building up of the crank. A portion A is roughly rounded to form the one end of the shaft, and the butt of the crank will present the appearance of a slightly elongated square, as shown at B, Fig. 25. The workman then "scarfs" or hollows it down at one edge all along the side, as shown in Fig. 26 from $A$ to $B$, and as indicated on the end view, Fig. 25, by the dotted line from $C$ to $D$; it will then present the appearance shown by the end view, Fig. 26, being somewhat bulged outward at the edges of the hollow. Three long thin slabs, forged and shaped for the purpose, are then placed on the hollowed part, the piece lying flat in the furnace. Fig. 27 represents the slabs $S$ thus placed in elevation, and Fig. 28 in section. These slabs are tupered a little, not in length but in cross section; and little pieces of iron are interposed between them, to keep the surfaces apart, and allow the flame free access between them. The object of making them thin is that they may be all equally heated, which is not so readily achieved when the slabs are thick; and the object of the tapering is to allow the slag to flow out freely when the uppermost slab is struck by the steam-hammer. The surfaces thus get solidly welded. The slabs are forged long enough to go right across the whole width of the crank, excepting about 6 inches; this margin is necessary to allow of the lengthening out of the slabs to the whole width under the process of forging. After these slabs are perfectly welded, the piece is turned upside down, and the process is repeated 
on the other side, as shown in Fig. 29. When welded down the mass has increased in depth as well. Another scarfing takes place on the first side, and then another on the second side, as shown in Figs. 30 and 31 , and so on, till the full size is obtained; and it will be seen, as in Fig. 32, that by this process of "scarfing" equally from both sides, the iron from the very middle of the body of the shaft (originally as at $\mathrm{E} \mathrm{F}$ in the end view, Fig. 25), is drawn up quite to the crankpin. The pin will show in section as the dotted line, Fig. 32 ; and it will be seen that by no possibility can there be "scarf end" in the crank-pin, as the slabs in all cases go right across the crank; and also that the cheeks of the cranks have no edge weldings crossing them, as in the previous cases, for the tail of a slab may be at $R$, while the other end may be at $S$, Fig. 32. The fibre is also developed by the continuous drawing out of the iron, consequent upon the repeated flat scarfings across the whole width of the crank. When the crauk has been thus massed sufficiently large, it is cut at the gable, with sufficient material left to piece out the other body of the shaft. This is now done, the coupling welded on, and a small stave drawn on the end to enable the forgeman to manipulate it, when it is turned end for end, to complete the other end, as shown already in Fig. 19.

This mode of proceeding occupies longer time than either of the other two methods, and consequently costs a little more; but the advantage is well worth all the difference, as greater confidence can bo entertained that the forging is every way satisfactory. In brief, by making the crank first, is avoided the liability to weakness at the neck, characteristic of the forgeman's making the shaft before him, as in the first method: by the repeated " side scarfings" is avoided the liability to fracture across the cheeks, consequent upon the edge weldings of both first and second methods; while by having the slabs the whole length of the width of the crank any "scarf end" in the length way of the crank-pin is impossible (such as may occur in the first method); and the mass of the crank being welded wholly on the flat must tend to form a more solid forging than if hammered otherwise. Thus, if the forging is well heated and properly hammered, the system promises to ensure that no weak part will be found in the shaft after it is finished and put to work. From the success which has already followed in every 
case the adoption of this method, the writer believes it will eventually be found that almost more depends on the mode in which a crank-shaft forging is constructed than on the material of which it is made.

This leads the writer to make some observations regarding the material for such shafts. It is of course well known that in the early days of engineering-before the time when steam navigation had received its great impetus by the invention of the screw-propellerthe connecting-rods, cranks, shafts, \&c.; of land engines were all formed of cast iron; except indeed where the connecting-rods were made of wood, strapped with plates of wrought iron, as frequently was the case with pumping, winding, and blowing engines. In fact all the parts that could be made of cast iron were so made, and the piston-rods, bolts, keys, straps, and other smaller parts were alone made of malleable iron; the smaller pieces being made from rolled bars direct, as at present, and the larger made of similar bars, but placed side by side and bound together or "fagoted," as they were called, from their resemblance to a fagot or bundle of sticks. These bars, thus fagoted, were either brought to a welding heat in a smith's hearth and welded under the sledge-hammers of the men called "strikers" or hammermen; or else were heated in a furnace, and welded under the tilt-hammer worked by a steam engine. Byand-by it was found necessary to adopt the stronger material, wrought iron, for parts hitherto made only of cast iron ; because the latter was found too deficient in tensile strength to stand the strains due to the power of high-pressure steam, which was now almost universally superseding the use of low-pressure steam in the condensing engine. The system of fagoting however was still carried out, even far into the history of marine engineering; but when the rapid increase in the dimensions of engines, both stationary and marine, called forth the steam-hammer, and so rendered the forging of heavy masses comparatively easy, the system of fagoting fell into disuse, for the following reason. In making up a fagot, say 18 or 20 in. square, it was found that the outside bars would reach a welding heat in the furnace much sooner than those in the 
middle; consequently on welding this fagot under the steam-hammer, though the blow might reach to the centre, yet the interior would not be welded, while the outer portion was; hence the shaft or other forging would not be welded throughout, and it was no uncommon thing for a shaft to break and expose the internal bars quite loose and separate from each other.

When it was seen that malleable was so much superior to cast iron, and that the system of fagoting was so imperfect, the adoption of "scrap iron," which was then composed principally of parings of boiler plates, pieces of cuttings from smiths' shops, old bolts, horse-shoes, angle-iron, \&c., became general. These being piled together in suitable pieces, and in a pile of suitable size for the convenience of working, were brought to a welding heat, and beaten out into a slab, or oblong-shaped piece, ready for the forgeman; who would build two or three together, adding more when required, and so bring out his piece to a sufficient size to enable him to shape his forging out of it. Then it was that engineers, seeing what an increase of strength they obtained by these means, invariably specified on their drawings (as many of them still do), "These forgings are to be made of carefully selected scrap iron, free from flaws and defects."

To meet the requirements of their customers therefore, forgemasters had now nothing to do but to select and use the best available scrap iron; but the universal adoption of iron hulls in place of wooden ones, conjoined with the rapid and unprecedented increase in steam navigation, soon introduced a class of scrap iron which did not possess the qualifications of good scrap; and also called for a very much greater supply of forgings than could be obtained in superior scrap iron. The consequence was that shafts of scrap iron, when turned and finished, became liable to exhibit streaks and seams, not due alone to imperfect welding in the forging, but likewise to the laminations and imperfections of the original scrap iron, which the process of piling and shingling into the slab was not sufficient to obliterate. So constantly does this yet occur, that it causes a strong temptation to make such forgings of new iron puddled direct from the pig and then shingled into slabs or 
blooms; under the idea that these streaks and seams will thus be avoided, and that the iron will be improved almost to the condition of scrap iron, while being forged under the steam-hammer. This however is found not to be the case. The forging is certainly free from the streaks of the scrap iron, but this freedom is obtained at the expense of strength; for the material is too raw; it wants cohesion, and has not had the proper kind or amount of working to bring it to the condition of superior wrought iron. This method is still further tempting, inasmuch as it is far cheaper than the other; the material costs less than scrap iron, and, as it welds at a lower temperature, a forging can be much more quickly and easily made. Still, for whatever class of machinery it may be fitted, it should certainly be eschewed in every case for a crank-shaft or propellershaft.

From these considerations it has been the custom at Lancefield, in the preparation of the iron for crank-shafts, to improve upon the ordinary condition of the scrap iron in the following manner. The pile is made up of carefully cleaned and selected scrap; it is brought to a welding heat, and then hammered under the steam-hammer. But instead of being beaten into a flat slab for the forgeman, it is beaten into a square billet, which is afterwards reheated and rolled in the rolling mill into a flat bar, as if for "best best" merchant iron. By this additional heating, hammering, and rolling, all the different qualities of the scrap iron composing the pile are merged into one homogeneous material, having the fibre given to it that was lost in the separated portions of the scrap iron; and this, when cut up into proper lengths, and again piled and shingled into the slab, results in a material possessing somewhat the oloseness and density of steel, while retaining all the toughness and tenacity of superior malleable iron. The improved method of constructing the forging, previously detailed, is worthy the use of this superior material; and both having been adopted at Lancefield with results which have commended themselves so unmistakably to many engineers, that they now not only specify the material but stipulate for the mode of manufacture, it is thought the system has only to be 
more widely known in order to be universally adopted. It is certain to give greater confidence in the endurance of such important parts of the machinery, although this confidence may have to be obtained by a small increase in the cost, due to the extra workmanship both on the material and on the forging.

Taking into consideration the vastly accelerated speed of the marine engine in late years, and the many disastrous effects which follow the breaking of a shaft at sea-also that the tendency of the age is still towards much higher pressures of steam, and further lengthening of stroke-it is not surprising that improvement in such an important part as the crank-shaft should be eagerly songht after; but it has hitherto been sought in the direction of the material alone. Cast steel has been adrocated, and brought to some extent into use; but its expense reuders such shafts costly out of all proportion to the other parts of the engine; while, in the event of their heating when at work (a very frequent casualty), and having the water-hose directed upon the crank-pin or journals, it cannot be expected that the material will behave any better than, or even so well as, tough wrought-iron. What is termed puddled steel is liable to the same objection, and probably, from its mode of manufacture, in a still greater degree. The so-called mild steel is no doubt proving itself a superior material, and yielding good results when rolled into ship or boiler plates. But thus prepared, it is more costly than "rolled scrap bar ;" and if not rolled, but cast into an ingot, then it possesses some of the crystalline characteristics of steel, with all the disadvantages attending its manipulation into a forging.

For extra large crank-shafts, the fear of unsoundness, arising from the ordinary mode of forging, has led some engineers to consider the propriety of building the shafts and cranks in separate pieces. This, with engineers generally, has not hitherto been looked upon with favour; as the fewer the pieces, the more rigid the shaft. Moreover the increased weight necessitated by this separate building is riewed as a disadvantage; even although it were not attended with greater cost, as undoubtedly it is.

The material and mode of manufacture adrocated in this paper may tend to dissipate some of these apprehensions. They will not 
obviate defective construction in the engines themselves, or faulty proportion of their parts, or neglectful supervision of their working; but they will reduce to a minimum the risk of breakage in such untoward circumstances. If any objection be taken on the score of extra size, the enterprise which a quarter of a century ago engaged in the making of the unusually large shafts necessary for the Great Eastern may still be trusted to meet the advancing requirements of the present day. In this connection the writer may quote the following extract from a letter of the late I. K. Brunel, dated 27th December, 1856, when the crank-shaft of the Great Eastern was being forged at Lancefield:- "I find I can work in the present connecting-rods with a crank-pin of 28 inches diameter, as per enclosed tracing, instead of 27 as the original one was ; and $I$ wish to be able to make it $28 \frac{3}{4}$ if I should so determine." This necessitated a diameter of 33 inches for the shaft, with the other dimensions correspondingly great. The shaft was successfully forged solid to that diameter, which has not since been attempted either in a solid or built form. The next largest size the writer knows of is in the Transatlantic service, and is $22 \frac{1}{2}$ in. diameter of crank-pin. The Orient, the latest large ocean steamer, has a crank-pin $20 \mathrm{in}$. diameter. It will be seen that between $22 \frac{1}{2}$ in. and $28 \frac{3}{4}$ in. there is a wide margin, which has yet to be made up, before the limit in size can be said eren to be approached.

\section{Discussion.}

Mr. E. WILLIAMs said that of forgings in a large way he knew but little, his business having been that of making jron and steel by rolling. It appeared to him however that the weak point in the system of forging now described was exemplified by Fig. 27, Plate 61, where the slabs were 6 in. shorter than the butt upon which they were to be welded. The reason given for this was that there might 
be room for the slab to lengthen or widen out, and cover the surface upon which it was to be fastened. That, judging from his experience of welding by means of piling and rolling, he thought a very doubtful mode of proceeding, because the extension or widening of the slab would take place after the body had become below a welding heat; the slab therefore would not be welded upon the body. He thought that, for a perfect weld, the slabs should be of full width; and if there was any widening out, the extra iron might be cut off afterwards.

Mr. J. I. K. J Amreson thought the members of the Institution were much indebted to Mr. Mcluean for bringing this subject before them : there were few men in Great Britain who had had so much experience as he had had in reference to forgings, and they might take it for granted that everything he had put before them was in the right direction. With regard to what Mr. Williams had said, experience was in this case everything; without it they could do nothing with large forgings. It was not however the question of the mode of forging that he would touch upon, but the way in which large forgings should be dealt with in the future: because there was no doubt a period had now been arrived at in the history of mechanical production when greater operations would have to be undertaken than ever before. The Old World would have to be connected much more rapidly with the New than it had been in the past; and he looked forward to a not distant day when steamers would leave Great Britain early in the week, and arrive in America at the latter end of it. Speaking of large forgings, it was said in the paper that the difficulty and expense of building up large shafts was very great. He had himself had some little experience in building up large shafts. One of the last ships turned out by the firm with which he was connected had a crank-shaft 56 tons in weight. It was built up in fifteen independent pieces : every crank cheek was separate, the crankpin was another portion, and the two ends were also separate; three such cranks constituted the crank-shaft of the ship. His impression was that they would still have to continue to deal with large shafts in pieces, because it was not a question of being able to make large forgings, but the difficulty arose from the fact that no marine 
engineer could run the risk of anything going wrong with a large shaft and the ship having to wait until another was finished; that was the difficulty to be met in dealing with. forgings of an excessive size. He wished to bring before the members the fact that the building up of large shafts, if they had capable tools, presented no difficulty whatever, and did not increase the cost. In the mechanical engineering of the future they would have to rely upon their tools for putting large pieces together much better than had been done formerly; and he believed there would be no difficulty in dealing with crank-shafts up to 100 tons, which he thought would have to be made within the next ten years.

Mr. J. WhITLEY believed that, when engineers required a 100-ton crank-shaft to cross the Atlantic Ocean in four days, they would not forge it, but would cast it. A beautiful illustration of theory successfully reduced to practice was given by Sir Joseph Whitworth in the manufacture of guns. Steel could be compressed into any form, and by doing so while it was in a molten or plastic state the interstices between the crystals, occupied by metallic vapours, were filled up, and it became a solid mass. Hence Sir Joseph Whitworth's column of steel $8 \mathrm{ft}$. high became only $7 \mathrm{ft}$. after the gases, which occupied spaces amongst the globules of the molten metal, had been pressed out and one homogeneous mass thus produced. So with regard to the crank-shaft; when hydraulic and pneumatic machinery was properly adapted, all crank-shafts would be made out of molten steel under pressure.

Mr. E. Rernolds said that, as the paper had directed attention to the most important subject of putting the slabs in the right way for making the hammering effective, he should like to mention one fact; because in his opinion the direction of many modern improvements was very seriously backwards. He was old enough to remember the time when in almost every engineer's works, among other things, Collinge axles used to be made for common road carriages. He used to have to turn such axles, and he knew the difficulties connected with them : namely that very frequently they went oval in case-hardening. 
He remembered being told of a great improvement made by the Patent Shaft and Axle-Tree Co. with the object of avoiding this difficulty of the shaft becoming oval in case-hardening. In mentioning their name he did not wish in any way to assail their deservedly high reputation. He did not even know if they now forged their axles in that way, or if any of the broken axles he had seen came from their works, as after the expiry of the patent the system became general. This system, as he knew it, was as follows. The old way of making a shaft was to pile a number of either square bars or flat slabs, and weld them together. The improved shaft (now probably forty years old) was made up by taking a central square bar and putting other segmental bars in some symmetrical form around it, so that the piling was central, and the bar when case-hardened did not become oval. But that introduced a most serious disadvantage: he had certainly known ten axles of that construction broken to one of those made in the old way. That might arise indeed from the great extent to which they had been introduced; but recently, within a few weeks, certain cases of break-down had come under his notice where the shafts were piled in that way. He maintained that it was an accident if a shaft made in that way was ever sound; in forging under the hammer it could not be hit fairly anywhere; it was nursed round and round with light blows, and knocked hollow as it went round: but this remark required some modification in the case of railway axles, which being required in large numbers were forged in proper swages, whereby the risk of unsoundness was greatly diminished.

The paper had to some extent challenged steel as a material for crank-shafts. His own firm had made steel shafts larger than any in England; and not one marine shaft ever made by them would fail to bear the following test:-taking the piece slotted out from the inside of the crank, a bar $1 \frac{1}{4}$ in. square cut out transversely from this piece, and not forged as was commonly done in iron shafts, would bear bending double without cracking; and would show when broken nothing that would look like crystal. He had never seen, and he believed nobody else had ever seen, a mass of wrought iron $2 \mathrm{ft}$. thick, in which a piece cut from the centre and broken across would 
not show exceedingly large crystals. Steel shafts would always be more costly than iron, for this reason amongst others : an iron shaft was built up in small pieces, and there was plenty of time while it was in the fire to balance it on the carrying tackle, because there was never much more than $10 \mathrm{cwt}$. laid on at a time; ten men at the staff were therefore sufficient to forge the largest crank, because there was plenty of time to adjust its balance, and only a little additional weight at a time was put on. But in the case of a steel shaft, say of 10 tons, the work had to be begun with an ingot, including the head, of 25 tons total, which kept altering its balance as the forging proceeded; and fifty men were therefore wanted at the handling bar to turn it round.

Something had been said by Mr. Whitley about crank-shafts being cast. Within the last week he had been informed by the eminent American engineer, Mr. Holley, that there were locomotives now running in America with shafts simply cast from the ingot steel. He did not say it was the wrong thing to do, because heary castings were so made, by his firm amongst others, which wonld certainly bend double in their cast state without cracking; there were some now in Glasgow of 4 tons weight; they would bend as far as the same material would after forging, and if properly treated they would have as little crystalline appearance when broken, the extent of that appearance being certainly much less than there would be in any wrought-iron mass of a similar size.

Mr. G. RATuFfa said the paper contained a very admirable description of the manner in which crank-shafts of the better qualities were forged. Ever since he had known the Mersey Iron and Steel Works, with which he was now connected, they had always manufactured their shafts on the last system described by Mr. McLean, except in regard to the point Mr. Williams had mentioned about the slabs being short of the butt; their slabs were all drawn to the length of the butt, and made in the crude state fully as long, or a little bit longer, than the finished web would be. There was then an opportunity, in finishing, of cutting a piece right out of a large lump, and it was a handy piece to put back into the ball furnace for making another crank. 
Mr. McLean had also mentioned that shafts were made from scrap, and that they were not so good when made from puddled iron, of which a great many shafts were now being made. On that point he differed from Mr. McLean, being of opinion that serap iron had been right in years gone by ; but now that there were all sorts of scrapcommon scrap, good scrap, \&c.-it formed a material of such a variable kind that it was not likely to be so useful as a more uniform metal. If common puddled iron were used, it made a common shaft; but if good cold-blast iron were used, the best iron shafts that could be made were produced. By using cold-blast iron the crystals would be as fine and small as in steel. He had cut pieces from crankshafts made with cold-blast pig-iron properly worked-several times worked before being put into the shaft-which would bend double when $1 \frac{1}{4}$ in. or $1 \frac{1}{2}$ in. square, as Mr. Reynolds had mentioned. Mr. McLean had also mentioned that puddled iron was cheaper than that made from scrap. He thought all present would admit that a shaft made from cold-blast iron was more expensive than a shaft made from serap. Scrap at the present time was almost valueless, but cold-blast iron maintained its price.

As to the cost of steel, he thought they ought to look a little further than the present time. There was the fact that steel rails not long ago were a great deal higher in price than iron rails, and yet it would be admitted that now they were cheaper; and it might readily be believed that it would be the same with shafts. He did not think that cheap steel shafts would be made in the way they were now made, by large ingots. He was of opinion that, no matter how a steel ingot was made, by compression or otherwise, there was a crystalline material to start with; and that all iron or steel in its young state was more or less crystalline. Without working there was no fibre, and without fibre in such a thing as a crank-shaft it was not safe to put it to work.

Mild steel had now come to such a pitch that, as Mr. Williams had often said, the question was where iron ended and steel began; ought it not to be called ingot iron and ingot steel? His own solution of the question was that steel was a metal which was cast in the fluid state: that would cover Mr. Williams's ingot iron and steel 
both. His firm were now making crank-shafts from a material of that sort, and they did not run the risk of having erystals. They made the ordinary sized ingots, and rolled them down to small bars, which were so mild that they could be cut up and piled exactly as Mr. McLean had said he piled his scrap. With this uniform steel they knew what they were using; and it would weld as weIl as wrought iron, without any flux, and would stand ten times the amount of blows in forging, the first time it was brought under the hammer. He had had a piece put under a straightening press, and bent it backwards and forwards over a hundred times, then nicked it and fractured it; and it was impossible to see the weld.

Mr. Jamieson had mentioned that it would be a very costly and awkward matter if any vessel had to wait for a large shaft. Perhaps it would be unwise for Mr. McLean or himself to pass any opinion as to whether a built-up shaft or a solid shaft was best; but he was quite certain that both of them would be most happy to make either.

Mr. Rrchard Peacoor said his experience in connection with crank-axles made for locomotive engines would go to prove that a crank-shaft made from good selected scrap, particularly boiler-plate shearings, would last longer and give a better mileage than shafts made from any other material he know of ; but he agreed with $\mathbf{M r}$. McLean that it was necessary to be careful in the selection of the scrap, not only to have it clean, which was an essential point, but to take care that the scrap itself was of the best material that could be obtained. There was nothing better than the scrap or shearings of Lowmoor boiler plates or best Yorkshire boiler plates, cut up into strips and piled in the usual way after being thoroughly cleaned.

Mr. A. McDonneli said, although he agreed with Mr. Peacock that a crank made of very good boiler-plate scrap was a very admirable thing, and would probably last exceedingly well, he doubted very much whether any iron shaft would equal one of cast steel. He had now in use 137 cast-steel crank-axles, and some of them had run 300,000 miles. Of that number only three had broken. One broke 
with a flaw in the centre, after running a very short mileage; the second broke in the ordinary place in the web of the crank after running 111,000 miles; the third did not break, but it showed a flaw, and as the engine was running with an express train he did not like to trust it any longer, and had it taken out and broken under the hammer. The flaw was in two places, about $1 \frac{1}{2}$ square inches in the cross section of the axle, the rest of the shaft being sound. He had been using those crank-axles for upwards of twelve years, and that was the total number of failures. He had also in use ten crank-axles made of Bessemer steel, all made in England by one maker. The cranks made by other Bessemer steel makers had all broken with an unsatisfactory mileage; but those which he had in use had run an average of 261,863 miles, and some of them as much as 300,000 miles; one he believed had exceeded 300,000 miles. He did not think any set of iron axles could be got to show such a result. But in considering the question of the breakage of crank-shafts, the way in which they were treated ought to be looked at, and not only the material of which they were made. He was quite satisfied that many locomotive engineers had themselves caused the failure of crankshafts, by turning the axles in an improper way, leaving too sharp corners or too sharp edges or something of that kind, which had caused them to give way. Large rounded corners should always be left in using steel.

Mr. Samson Fox said from his own experience in the making of forgings, he held the opinion that fibre was the one thing which should be attended to above all others, because if they had fibre they could at any time twist the shaft backwards and forwards without fear of breaking it straight off. There was no doubt that, in the very heavy work they were coming to, they required parts of engines to be made of almost any size, without having to risk local strains or any cause of breaking off short. He had seen the shaft which Mr. Jamieson had mentioned, and he considered it was a very fine job, and a step in the right direction for heary work-a shaft built up in parts and well fitted together with good machinery; that was the right way to go about it for heary work. With regard to smaller 
shafts, there was no doubt that with forgings made from very good material-cold-blast iron, for instance-they would get a very good job. Purity of material was the first thing, and then plenty of work on it.

Mr. J AMEs HowDen had used a large number of crank-shafts built up on the system described by Mr. MeLean, and could therefore speak with confidence of their good quality. There could be no doubt that the manner in which a shaft was built up, quite apart from the material itself, was a matter of great importance in determining its soundness and durability. As far as his own knowledge extended, after making many enquiries, he was not aware that crank-shafts had been made elsewhere on the careful system. described by Mr. McLean. With regard to the material, he thought perhaps there had not been sufficient recognition of the value of the rolled scrap iron, a material which in his opinion was fully equal to steel for such forgings. Since its introduction by the Lancefield Forge Co., now a good many years ago, his own firm had never had a shaft made of any other material, so far as he knew; and certainly they had never had a breakage of a shaft in any steamer, although their largest shafts, subject to the greatest strains, had been made on that system. Only in one case was a flaw discovered after a working of six or eight months; it necessitated the removal of the shaft, but in no way detracted from its strength or efficiency : it was merely a surface defect.

Mr. Molfan was very much obliged for the careful attention that had been paid to his paper. He might mention at the outset that it was not his desire to raise any question between iron and steel, except so far as price was concerned. He had stated in his paper that steel shafts were very costly, out of all proportion to iron shafts : therefore he might say that the scope of his paper had been a little misunderstood on that point. If he were asked to make forgings of steel, well and good, he would do so; but the tracings for engine forgings addressed to his own and other forges always specified that the forgings were to be made of "carefully selected 
scrap iron "- "scoured" in some cases, and "cleaned" in othersshowing that engineers generally had still a thorough determination to have their forgings made of scrap iron, instead of new iron or steel. With regard to the rolled scrap bar, he had been gratified within the last day or two at receiving some tracings for large forgings from a leading firm, in which for the first time they specified. rolled scrap iron both for the crank-shaft and propeller-shaft. No doubt they were convinced that by the additional working given to the scrap iron in rolling the billet into bars, the inequalities were got rid of and a more homogeneous and reliable metal was obtained.

With regard to Mr. Williams's remark about the length of the slabs, he had tried various methods; but he had made shafts on the system described for several years, and with the best results. He found that the thin slabs came to a welding heat much quicker than the body : the interstices allowed the flame to play through and bring the surfaces to a welding heat, and the consequence was that the slabs got perfectly welded. The making these slabs the whole width of the body of the crank was in the wrong direction for economy. For the slabs, being much thinner than the body they were being welded to, must necessarily draw under the hammer to a greater extent, and the consequence would be that the first two or three blows of the hammer would send part of the iron over the edge of the piece, hanging down as shown in Fig. 33, Plate 61 ; which would of course be cut away as useless, and if repeated at each lay of the slabs would involve great and unnecessary waste.

He would not enter into the questions that Mr. Whitley had brought forward as to compressed steel and large ingots, because, as he had said, manufacturers were obliged to conform to the requirements of customers. So long as engineers specified scrap iron, in preference to any other material, manufacturers must be ready to obey their behests; and while this was so, his object was to create still greater confidence, and to improve the character of scrap iron by rolling the billets as described. Cranks of rolled scrap iron cost a little more than those made of ordinary scrap; but where a shaft was specified to be made of the very best scrap, he generally used rolled scrap for the purpose. 
Mr. Reynolds had taken up his remarks regarding steel shafts a little too warmly. H $H_{\theta}$ had merely meant to say he did not think that, in the case of the cooling of beated bearings with water (as was frequently necessary with crank-shafts at sea), the behaviour of steel shafts under those circumstances would be any better than, or even so good as, that of wrought-iron shafts.

He was much obliged to Mr. Jamieson for the complimentary manner in which he had spoken of this system. If the building up of crank-shafts was to be carried further in the future, he was quite ready to make them. He had built several, but his experience was something like Mr. Ratliffe's; the building up of the shaft rendered it more expensive than a solid shaft would be, and the weight was much greater. He was glad to know that Mr. Ratliffe had been making shafts in the way he had described: his own objection to puddled iron was only when it was used in the slab, without being rolled; after rolling it was no doubt in a condition approaching that of scrap iron. $\mathrm{H}_{e}$ did not desire to monopolise any improvement himself, and the very object of bringing forward his paper had been that other engineers might become acquainted with a process which he had every reason to believe was a step in the right direction.

The President said that, in asking the meeting to accord to Mr. McLean their thanks for the paper he had brought before them, it might perhaps be expected that he should make some reference to the paper itself. He would however forbear from any criticism, and would merely mention one or two points with regard to the observations that had fallen from other gentlemen.

As to Mr. Williams's objection to the way in which the slabs were laid on the body of the crank-shorter than the body itself,-this seemed rather like a plan of welding which was advocated by a gentleman well known and respected by them all, Mr. Ramsbottom of Crewe, by whom some years ago a process of welding by friction had been practised. It appeared to him that that very process of welding by friction took place in the system adopted by Mr. McLean : as the two surfaces slid upon each other, they became incorporated into a solid mass, and the welding might be expected to be complete. 
With regard to Mr. Peacock's observation as to the quality of scrap iron, Mr. McLean had remarked that engineers still asked for cranks to be made of scrap iron, but that the difficulty now-a-days was to get decent scrap; and that this difficulty was got over by taking the scrap, heating and rolling it, cutting it up, and re-scrapping it. Mr. Peacock had stated that he found boiler plate of the Yorkshire quality gave the best scrap iron. In the case of Mr. Peacock's firm, and his own, or any other firm who made boilers of Yorkshire quality, of course it was comparatively easy to select their own scrap from their own plates, and they took good care that no foreign scrap was inserted : the result was that the necessity Mr. McLean had mentioned. did not exist in cases of the kind referred to by Mr. Peacock. They were able to get good serap; and therefore, so far as material was concerned, they were able to make comparatively good crankshafts.

It might be within the experience of many gentlemen present, that there was a reaction at the present day from the idea of adopting cast-steel crank-shafts or Bessemer-steel crank-shafts, and they were now being driven back to scrap iron. No doubt that was right, but it was not altogether what he looked for in the future. They talked of steel as if it was one material; but it had as many qualities as iron; and it therefore depended not only upon the selection of material, but upon the mode in which the material was worked, whether they got a good result or not. Many years ago the late Mr. Kitson and himself had been called upon to deal with a cast-steel crank-axle which had caused an accident on a railway near London. When they came to look at it they found seven flaws-all incipient flaws-none of which could be observed otherwise than microscopically. Now every one knew that in the case of locomotive engineers it was impossible that foremen with microscopes could examine every crankaxle daily before it left the works. He was therefore pleased to find from Mr. McDonnell, who had a large number of those steel crankaxles, that the defects which then seemed to have developed themselves in those axles (which had been of a very high price) were apparently got over; and he hoped the day would come when we should get a homogeneous metal like steel, and so avoid the dangers which he 
feared would arise from mixing different qualities of iron. Mr. Molean got over the difficulty by re-working his scrap iron before putting it into the crank-shaft; and Mr. Ratliffe, of the Mersey Steel and Iron Works, said that in order to get over the serap difficulty he got a higher quality of puddle-bar made from cold-blast iron, and dealt with it as Mr. McLean did with his rolled scrap. He called attention to those facts, because of the lessons that might be derived from the experience of others in getting over the difficulties arising from want of homogeneity in the material used. He hoped Mr. Reynolds's anticipations would be confirmed, and that they would get a homogeneous material, whether called steel or iron, which would give large sound masses, as to which there would be less danger of their being found fault with on account of either surface flaws or interior defects.

He was quite sure the meeting would accord their heartiest thanks to Mr. McLean, not only for his paper, but for the great pains he had taken, without any assistance from the Institution, in producing the drawings which so fully exemplified his mode of manufacture.

The vote of thanks was passed by acclamation.

The following paper was then read :- 
FORGING OF CRANK SHAFTS.

Plate.59.

Fiog. 1.

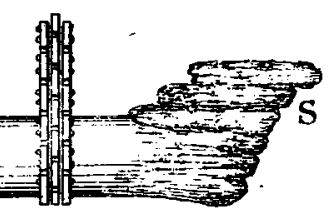

Fip 2.

$+5$

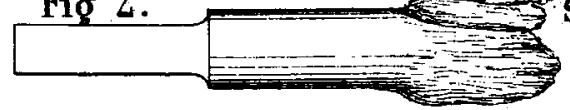

Fig. 3.
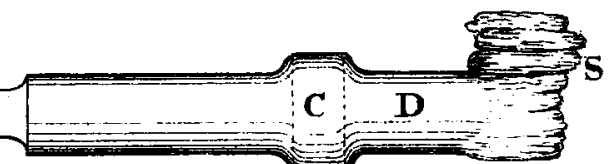

Fig. 7.

Fig. 5.

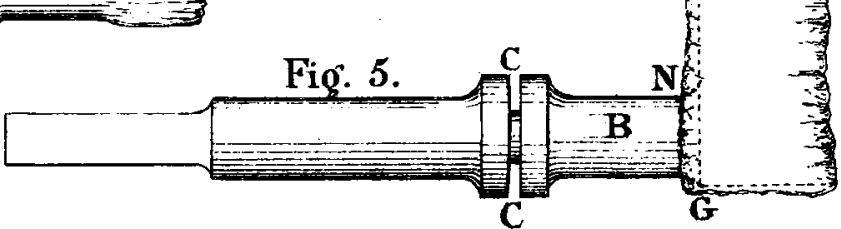

Fig. 4.

(Arrceedings lnst. M.E. 1879.)

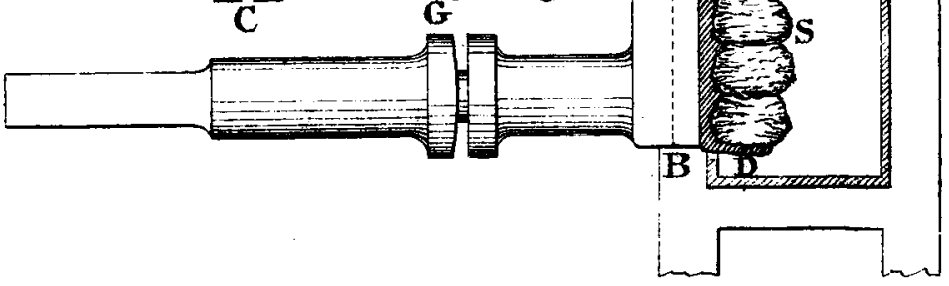

i 


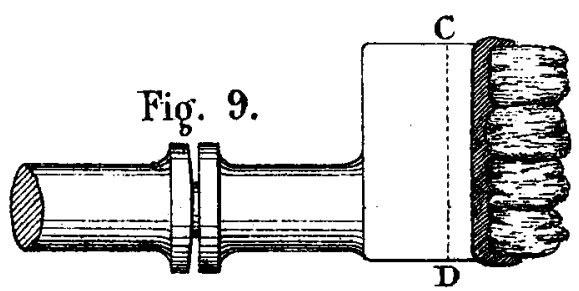

Fio. 10.
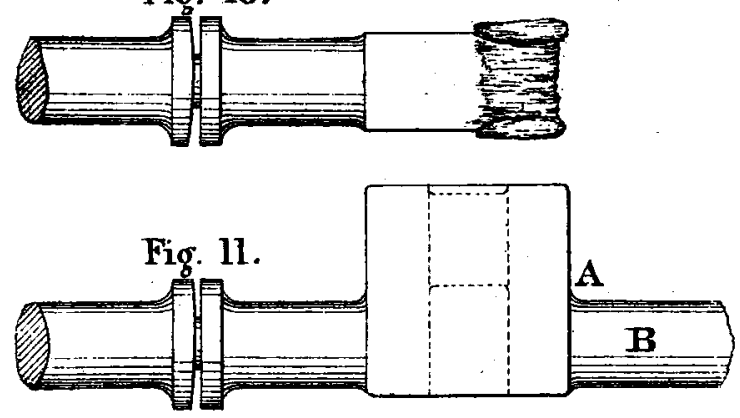

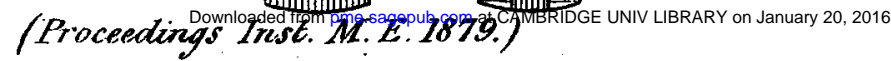
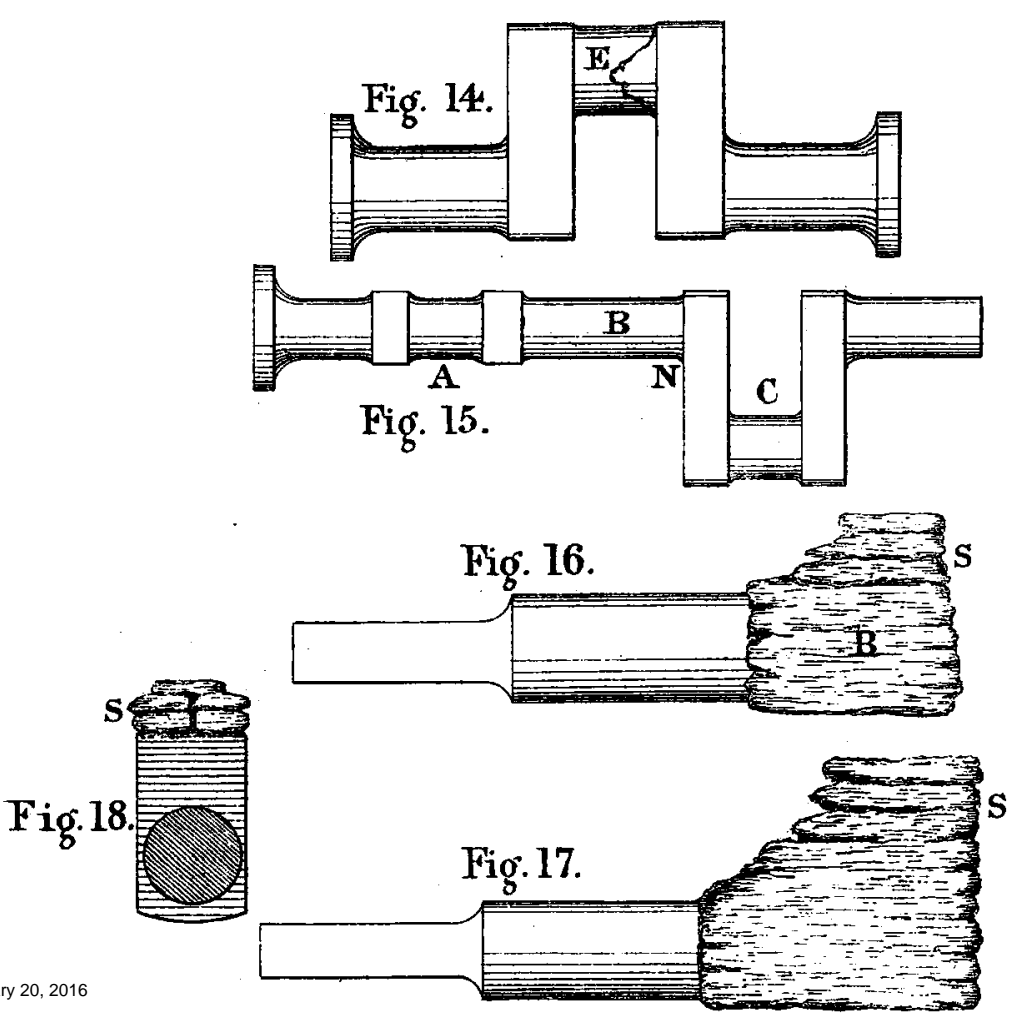

है



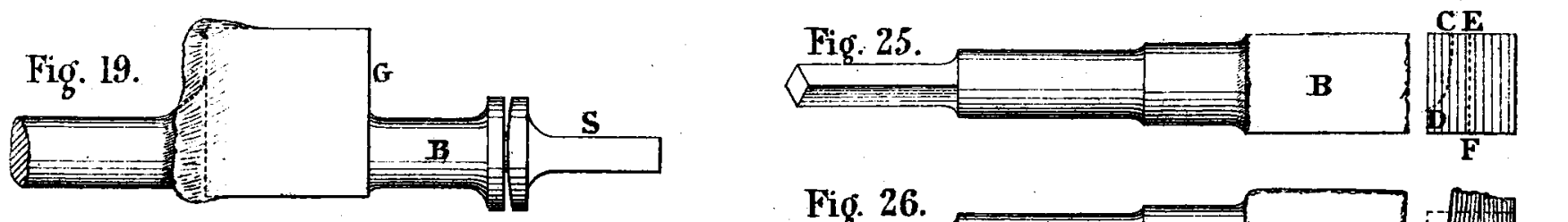

Fig. 20.
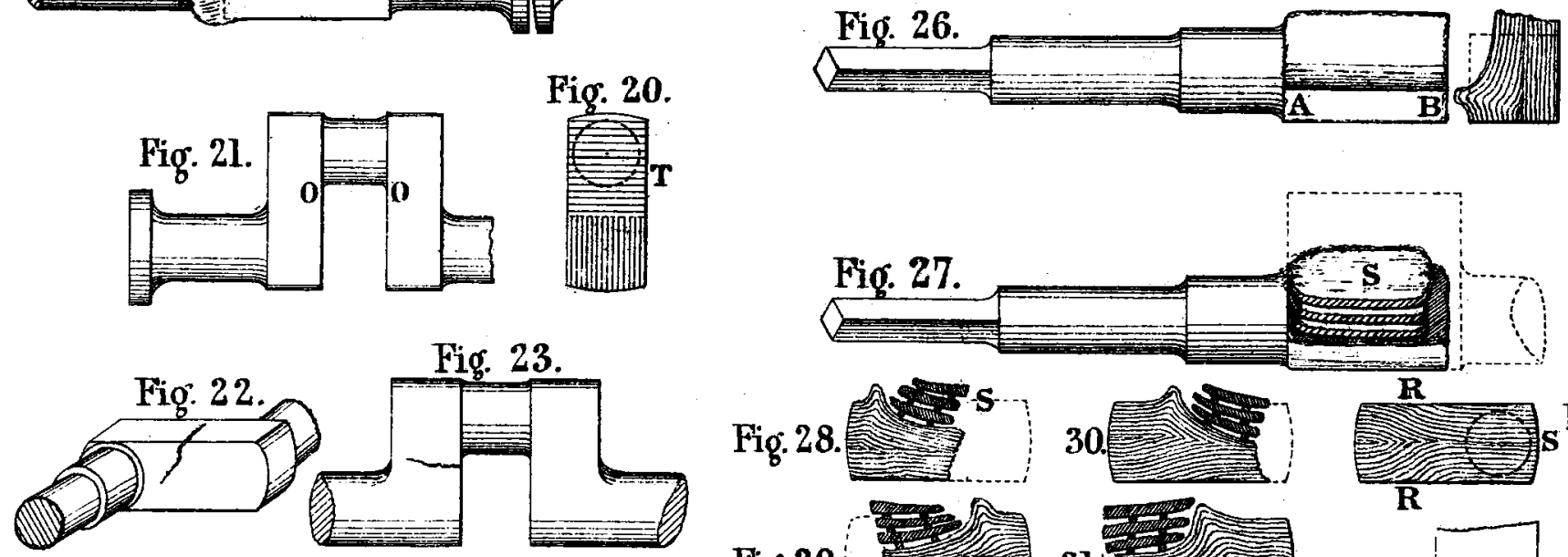

Fio. 24.

Fig. 28.
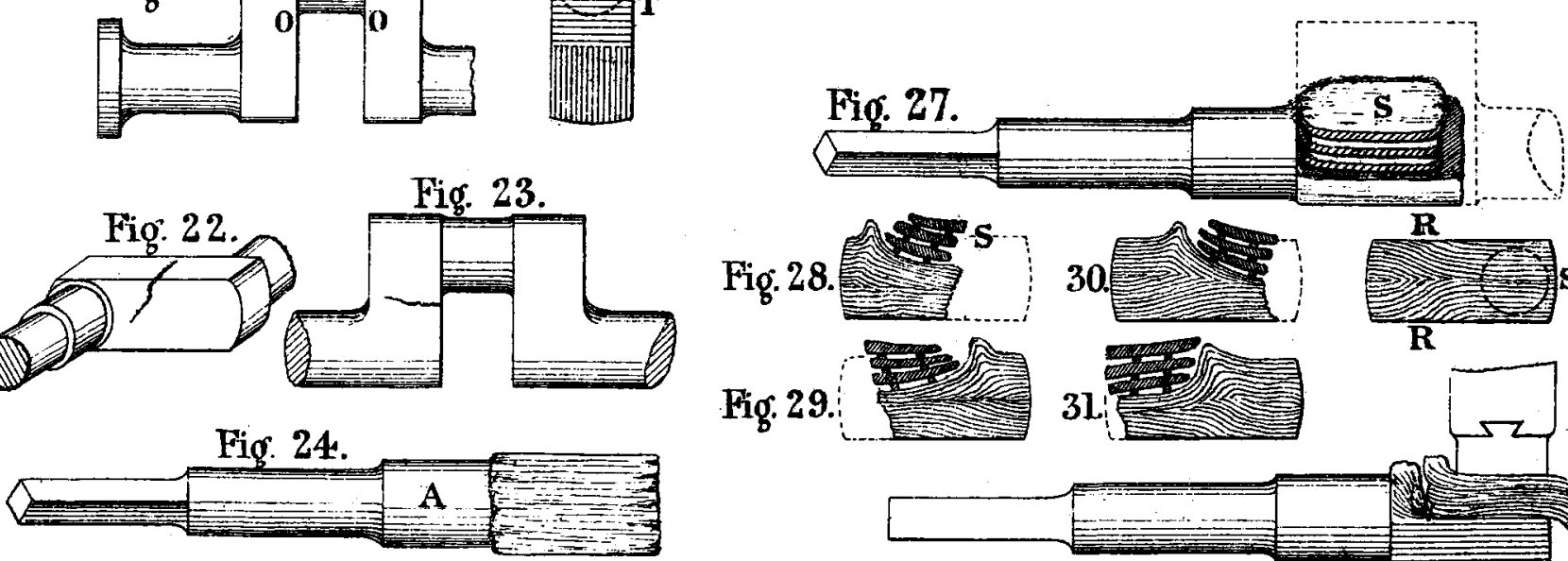

Fig. 29.
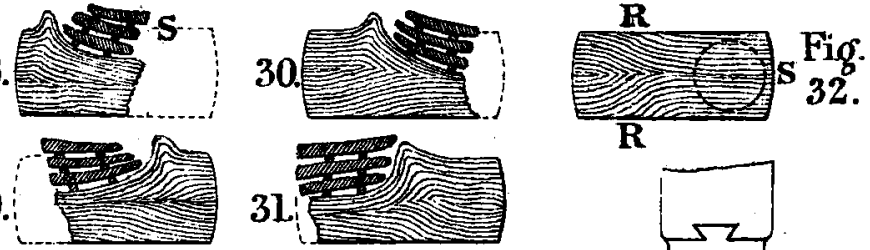

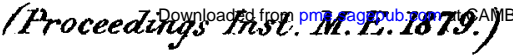

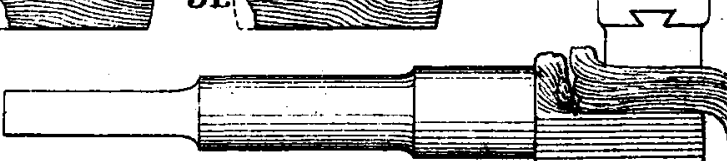

Fig. 33. 